\title{
Nonfunctioning adrenocortical carcinoma: a study of 12 cases
}

\author{
Ghanghoria $\mathrm{S}^{1}$, Raje $\mathrm{P}^{1}$, Jain $\mathrm{R}^{1}$, Ghanghoria $\mathrm{A}^{1}$ \\ ${ }^{1}$ Department of Pathology, Mahatma Gandhi Memorial Medical college, Indore, Madhya Pradesh, India
}

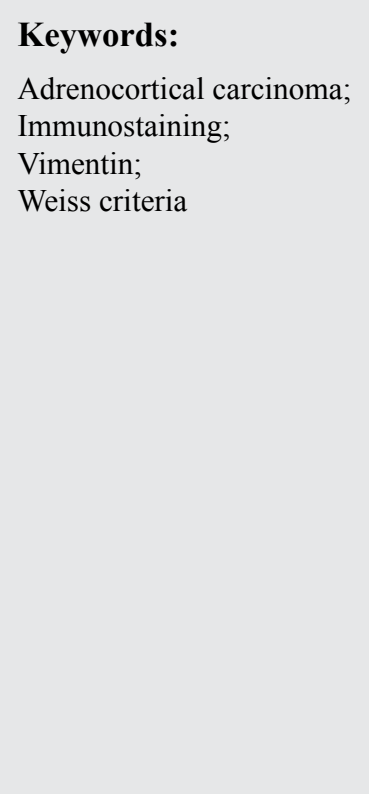

\begin{abstract}
Background: Adrenal cortical carcinoma is a rare malignant tumor. Several systems were proposed for diagnosis and evaluation of adrenocortical tumors. Weiss system is most commonly used method for assessment of malignancy, but only few studies has applied this criteria, for assesement of prognosis. The aim of this study was to analyzethe histological features \& immunostaining status of adrenocortical carcinoma diagnosed according to Weiss criteria and correlate the data with patient clinical finding and outcomes.
\end{abstract}

Materials and Methods: In this study clinicopathological features of 12 cases were reviewed and diagnosed as adrenocortical carcinoma on the basis of Weiss criteria and immunostaining. Grading was done according to the nine histopathological criteria of Weiss and is applied for assessment of prognosis. Each tumor was labeled malignant, when it scored $\geq 4$ point of this histological criteria, tumors with $\leq 3$ points were considered as adenoma and not included in the series. Immunostains applied were, Vimentin, Cytokeratin, synaptophysin, chromogranin, Vinyl mandilic acid, epithelial membrane antigen and Melan A.

Results: All cases studied, presented at least four of the Weiss criteria and thus diagnosed as adrenocortical carcinoma. Patients with 7 and more score of Weiss criteria is considered as high grade carcinoma. Immunostains, have role in the diagnosis of adrenal cortical tumor, but does not have any significant clinical outcome.

Conclusion: Weiss criteria was found to be a good prognostic factor in adrenal cortical carcinoma.

\section{INTRODUCTION}

Adrenal cortical carcinoma (ACC) account for approximately $0.02 \%$ of all malignancies. ${ }^{1}$ Most adrenocortical tumours are benign. Nevertheless differential diagnosis between benign and malignant adrenocortical neoplasm of adults is difficult and an assessment of clinical and pathological parameters is necessary for the differentiation. Clinical parameters

\section{Correspondence:}

Dr. Shikha Ghanghoria, $M D$

Assistant Professor, Department of Pathology, MGM Medical College, MY

Hospital \& Cancer Hospital, Madhya Pradesh, India

Email:drshikha78@gmail.com include weight loss, increased urinary 17 ketosteroid excretion and unresponsiveness to ACTH stimulation., ${ }^{2,3}$ In adults the histological differentiation is currently based on the criteria suggested by Weiss et al. (Weiss criteria). ${ }^{4}$ Grossly, both adenomas and carcinomas are solitary, but adenomas rarely exceed $5 \mathrm{~cm}$ in greatest diameter. Most carcinomas weigh more than $10 \mathrm{gm}$ and some may reach $1000 \mathrm{gm}$ or more. ${ }^{4}$ In addition a tumour mass larger than $100 \mathrm{gm}$ reported to be associated with malignancy. On cut section, usually ACC show variegated pattern with necrosis and hemorrhage. Microscopically carcinomas exhibit a wide range of differentiation, from tumors that are well 
Table 1: Weight of tumors, Weiss criteria and immunostainings results

\begin{tabular}{|c|c|c|c|c|c|c|c|c|c|c|}
\hline Case \# & $\begin{array}{l}\text { Weight } \\
\text { (Gms ) }\end{array}$ & $\begin{array}{c}\text { Weiss } \\
\text { criteria }\end{array}$ & $\begin{array}{c}\text { Synapto } \\
\text { physin }\end{array}$ & Vimentin & $\begin{array}{c}\text { Cyto } \\
\text { keratin }\end{array}$ & $\begin{array}{c}\text { Chromo } \\
\text { granin }\end{array}$ & VMA & EMA & C kit & Melan A \\
\hline 1 & $300 \mathrm{~g}$ & $8 / 9$ & + & + & - & - & - & - & - & + \\
\hline 2 & $40 \mathrm{~g}$ & $4 / 9$ & + & + & Weakly + & - & - & - & - & + \\
\hline 3 & $65 \mathrm{~g}$ & $5 / 9$ & + & + & - & - & - & - & - & + \\
\hline 4 & $400 \mathrm{~g}$ & $8 / 9$ & + & + & - & - & - & - & - & + \\
\hline 5 & $\mathrm{NA}^{*}$ & $7 / 9$ & + & + & - & - & - & - & - & + \\
\hline 6 & $100 \mathrm{~g}$ & $6 / 9$ & + & + & - & - & - & - & - & + \\
\hline 7 & $80 \mathrm{~g}$ & $5 / 9$ & + & + & - & - & - & - & - & + \\
\hline 8 & $\mathrm{NA}^{*}$ & $6 / 9$ & + & + & - & - & - & - & - & + \\
\hline 9 & $\mathrm{NA}^{*}$ & $5 / 9$ & + & + & - & - & - & - & - & + \\
\hline 10 & $50 \mathrm{~g}$ & $6 / 9$ & + & + & Weakly + & - & - & - & - & + \\
\hline 11 & $60 \mathrm{~g}$ & $5 / 9$ & + & + & - & - & - & - & - & + \\
\hline 12 & $100 \mathrm{~g}$ & $6 / 9$ & + & + & - & - & - & - & - & + \\
\hline
\end{tabular}

* The tumor was inoperable

Table 2A: Tumor scores based on Weiss criteria

\begin{tabular}{|c|c|c|c|c|c|c|}
\hline Weiss criteria & Case \#1 & Case \#2 & Case \#3 & Case \#4 & Case \#5 & Case \#6 \\
\hline High nuclear grade & + & - & + & + & + & + \\
\hline Mitotic rate / $50 \mathrm{hpf}$ & 25 & 10 & 10 & 32 & 15 & 14 \\
\hline Atypical mitoses & + & + & + & + & + & + \\
\hline Eosinophilic tumour cell cytoplasm & + & + & + & - & + & + \\
\hline Diffuse architecture & + & + & + & + & + & + \\
\hline Necrosis & + & - & - & + & + & + \\
\hline Venous invasion & + & - & - & + & - & - \\
\hline Sinusoidal invasion & - & - & - & + & - & - \\
\hline Capsular invasion & + & - & - & + & + & - \\
\hline Total & $8 / 9$ & $4 / 9$ & $5 / 9$ & $8 / 9$ & $7 / 9$ & $6 / 9$ \\
\hline
\end{tabular}

Table 2B: Tumor scores based on Weiss criteria

\begin{tabular}{|c|c|c|c|c|c|c|}
\hline Weiss criteria & Case \#7 & Case \#8 & Case \#9 & Case \#10 & Case \#11 & Case \#12 \\
\hline High nuclear grade & + & + & + & + & + & + \\
\hline Mitotic rate / $50 \mathrm{hpf}$ & 18 & 10 & 12 & 14 & 10 & 13 \\
\hline Atypical mitoses & - & - & - & + & + & + \\
\hline Eosinophilic tumour cell cytoplasm & + & - & + & + & + & + \\
\hline Diffuse architecture & + & + & + & + & + & + \\
\hline Necrosis & + & + & - & + & - & + \\
\hline Venous invasion & - & + & + & - & - & - \\
\hline Sinusoidal invasion & - & + & - & - & - & - \\
\hline Capsular invasion & - & - & - & - & - & - \\
\hline Total & $5 / 9$ & $6 / 9$ & $5 / 9$ & $6 / 9$ & $5 / 9$ & $6 / 9$ \\
\hline
\end{tabular}

differentiated to totally undifferentiated neoplasm composed of giant cells with abundant acidophillic cytoplasm and bizarre hyperchromatic nuclei. Immunohistochemically, adrenocortical adenoma (ACA) show a greater expresion of low molecular weight keratins and a lesser expresion of vimentin. Therefore, tumor that is strongly positive for vimentin and negative or weakly positive for keratin is likely to be a carcinoma. ${ }^{6,7}$ Furthermore a high tumour proliferating action (TPF) indicated by $\mathrm{Ki} 67$ staining and positive p53 protein staining has also been reported to favor malignant behaviour and to be of great assistance in the differential diagnosis. ${ }^{2,8}$ ACC should also be differentiated with renal cell carcinoma invading the adrenal gland. Strong positivity for Epithelial Membrane Aantigen and cytokeratin favors renal cell carcinoma, whereas positivity for Melan-A and synaptophysin favors ACC.,10 Among 
the various criteria proposed, the one proposed by Weiss, which requires only histopathological findings, has been most widely employed. Nine criteria are high nuclear grade, mitotic rate, atypical mitotic figures, eosinophilic tumor cells, diffuse architecture, necrosis, venous invasion, sinusoidal invasion and capsular invasion. The tumors with $\leq 3$ of these histological criteria were classified as ACA, those with $\geq 4$ of these histological criteria were classified as ACC.

In the present study we analyzed the histological features \& immunostaining status of adrenocortical carcinoma diagnosed according to Weiss criteria and correlated the data with patient clinical finding and outcomes.

\section{MATERIAL AND METHODS}

This study comprised 12 cases of ACC admitted in Mahatma Gandhi Memorial Medical college Indore and Bombay Hospital, Indore. Clinical and operative findings, gross findings and follow-up data were obtained from hospital record.The histological features of the hematoxylin and eosin (HE) stained sections of the tumours were reviewed, and the cases were diagnosed as ACC on the basis of Weiss criteria and Immunostaining.

The 9 Weiss histopathologic criteria of malignancy were precisely defined and carefully assessed for each tumor: ${ }^{4}$

1. Nuclear grade: Nuclear grade III and IV are considered as high grade as per the criteria of Fuhrman. ${ }^{1}$ Same is applied for Weiss criteria.

2. Mitotic rate: should be greater than 5/50 High power field (HPF). According to Weiss, "mitosis was evaluated by counting 10 random HPF in the area of the greatest numbers of mitotic figures on the 5 slides with greatest number of mitoses. If $<5$ slides were available for a case, a correspondingly greater number of fields per slide were used to make 50 HPF."

3. Atypical mitotic figures: "an abnormal distribution of chromosomes or an excessive number of mitotic spindles."

4. Eosinophillic tumor cell cytoplasm: Presence of eosinophilic cytoplasm in $>75 \%$ of tumour cells is mandatory.

5. Diffuse architecture: "if $>1 / 3$ of the tumor formed patternless sheets of cells." Trabecular, columnar, alveolar or nesting organizations were regarded as nondiffuse patterns.

6. Necrosis: Necrosis is regarded as present when occurring in at least confluent nests of cells.

7. Venous invasion: Weiss defined a vein as an "endothelial-lined vessel with smooth muscle as a component of the wall."

8. Sinusoid invasion: A sinusoid is defined as "endotheliallined vessel in the adrenal gland with little supportive tissues." Only sinusoids located within the tumor are considered.

9. Invasion of tumor capsule: "invasion of the capsule was accepted as present when nests or cords of tumor extended into or through the capsule, with a corresponding stromal reaction."

Each Weiss criteria was scored 0 when absent and 1 when present. Thus, each tumor was graded from 0 to 9 , determining a total Weiss score. ${ }^{4}$ Most of the cases presented with $\geq 4$ of 9 items of Weiss criteria were classified as ACC. Immunohistochemistry applied was vimentin, cytokeratin, synaptophysin, chromogranin, Vinyl Mandilic Acid, Epithelial Membrane Antigen and Melan A.

\section{RESULTS}

The present series included 12 case of ACC. The age ranged from 25 years to 60 years. The sex distribution in patient's were almost similar, with slight female predominence ( 5 males and 7 females). Clinically all patients presented as nonfunctioning tumors. Hormonal levels of all the cases were normal. The weight ranged from $40 \mathrm{gm}$ to $400 \mathrm{gm}$, while weight of three cases were not available since the tumors were inoperable (Table 1). The size of the tumors range from 6 to $23 \mathrm{~cm}$ (fig. 1A). Cut section of most of the tumors were grey red, while few cases show areas of necrosis and hemorrhage (fig. 1B). The tumor cells showed diffuse pattern of pleomorphic cells with eosinophilic cytoplasm (fig. 2\&3). Areas of tumor necrosis with pleomorphic tumor cells were also seen (fig. 4). Acidophillic cytoplasm and mitotic rate greater than 5/50 HPF is seen in almost all cases. Using Weiss criteria it was found that all cases possessed $\geq 4$ score, and 3 cases ( $25 \%$ ) had $\geq 7$ score.

All the cases were showing strong positivity for vimentin, Melan-A and synaptophysin, while cytokeratin is weakly positive in one case with Weiss score 4 (Table 1).

The patients were followed up over a period of 2 months to 60 months. Follow up was avaliable in 10 out of 12 cases. Of these 10 patients, 2 died over a follow up period of 4 months, both of these cases scored 8 . Two patients developed metastasis in lung, they were with Weiss score 5 and 6 with venous invasion. One patient showed metastasis in liver with score 7. Two patients were lost to follow up. Five cases were alive after 55 months of surgery and chemotherapy, these cases were with score of 4 and 5. Detail of the Weiss score is shown in Table $2 \mathrm{~A} \& \mathrm{~B}$.

\section{DISCUSSION}

ACC is a rare tumour with an incidence of about 1 to 2 cases per million population. ${ }^{2}$ They represent a high grade entity and its overall five year survival rate is reported to be from $16 \%$ to $32 \%{ }^{3}$ Most of the non-functioning adrenocortical lesions seen as surgical specimens are carcinomas. ${ }^{12}$ ACC may be classified as non-functioning and functioning 


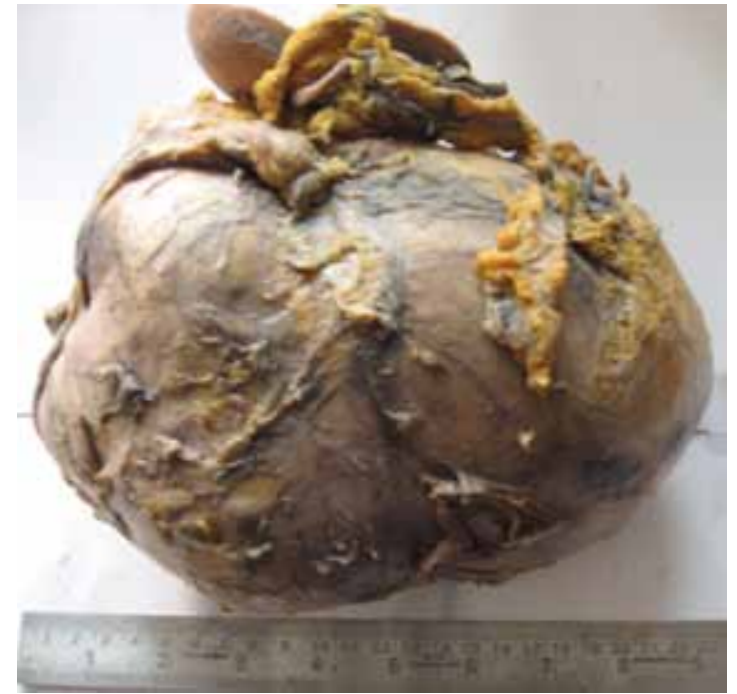

Figure 1A: Gross photograph of large adrenocortical carcinoma

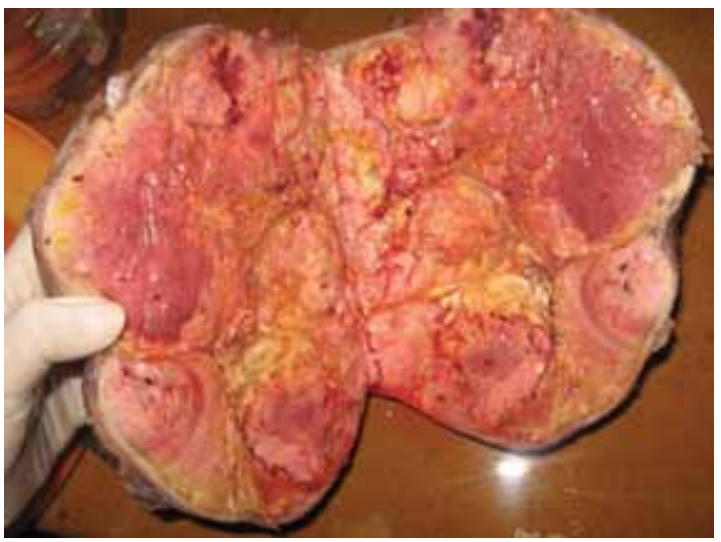

Figure 1B: Cut surface of the mass showing variegated appearance with areas of necrosis.

according to the clinical syndromes with which they are associated, like Cushing syndrome, Conn's syndrome. ${ }^{2,8}$ This series do not show any clinical features of functioning tumors. These nonfunctioning tumors are difficult to diagnose and to suspect its origin from adrenal gland. Some authors have found no differences between the two types, on histology, ${ }^{14}$ while others have found a cord like and alveolar pattern in cases without a hormonal syndrome. Pathological differentiation between benign and malignant adrenocortical tumours has been based on Weiss criteria as well as vimentin immunostaining \& tumour size. ${ }^{3,4} \mathrm{In}$ the present series all tumour satisfied the Weiss criteria for a carcinoma and tumour necrosis, vascular, capsular invasion seemed to be correlated with a worse prognosis. (33.33\%of cases). On the other hand the mitotic count and atypical mitoses seemed irrelevant to the patient outcomes. Large tumour size indicates the possibility of malignancy. Vimentin immunostaining was diffusely positive in all cases. Although the Weiss criteria are widely used and helpful in distinguishing malignant from benign, sometimes it is difficult to predict the biological potential of a tumour

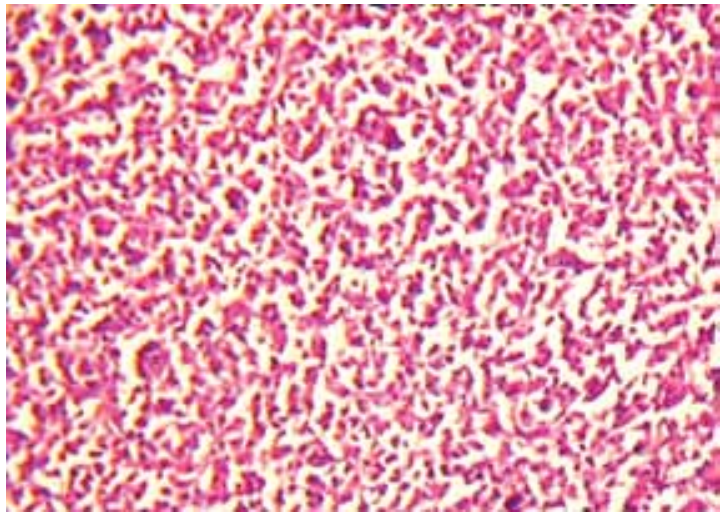

Figure 2: Photomicrograph of adrenal cortical carcinoma showing diffuse pattern of pleomorphic cells with eosinophilic cytoplasm (HE stain, X10).

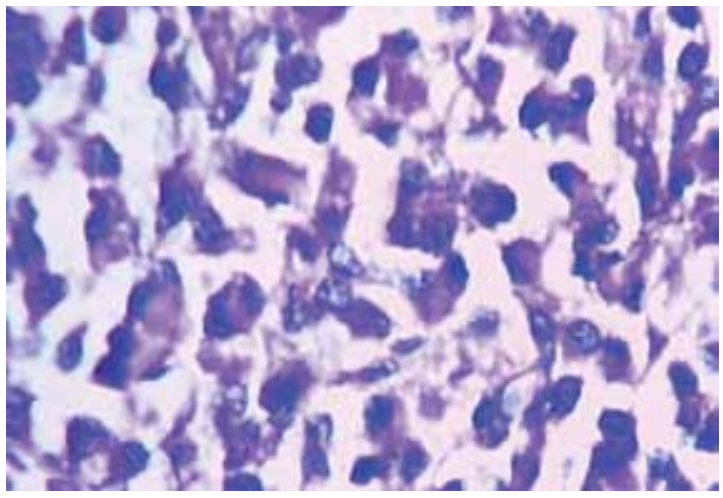

Figure 3: Photomicrograph of adrenocortical carcinoma showing tumor cells with hyperchromatic nuclei (HE stain, X40)

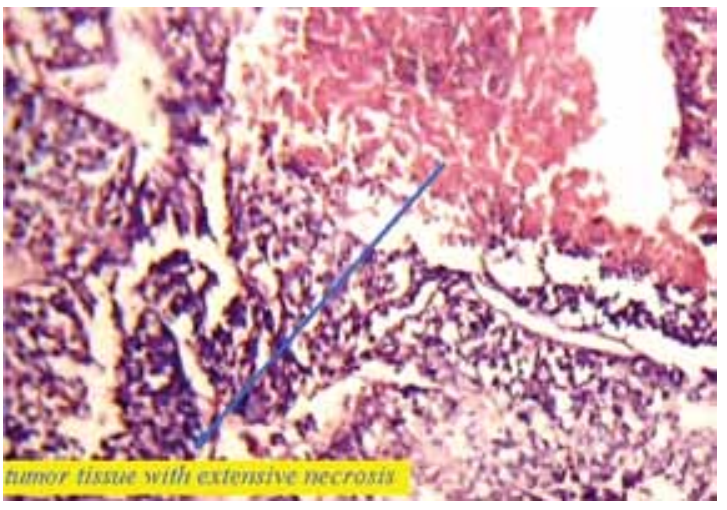

Figure 4: Photomicrograph showing tumor necrosis with pleomorphic tumor cells (HE stain, X10).

diagnosed by these criteria. The two most common sites of distant metastasis are the lungs $(53 \%)$ and the liver $(44 \%)$. Metastases to the bones and brain are unusual. ${ }^{15} \mathrm{We}$ have noticed metastasis in lung and liver. Early surgical resection is the key to the cure. ${ }^{16}$ In our study $50 \%$ cases underwent surgical resection, out of which $17 \%$ showed mortality. Aggressive surgical resection of metastasis may be beneficial. ${ }^{17}$ Combination of surgical treatment and chemotherapy has been advocated for recurrent disease. ${ }^{18}$ The role of radiation alone has little documentation in literature. In present series surgical resection and 
chemotherapy are the mode of treatment considered according to the aggressive behavior of the tumors. The median survival is 2 years. However, there is variation in survival according to the histologic grades. In one of the study, Grade III cases survived for one month while Grade II survived for 51 months after surgical treatment. ${ }^{19}$ In present series almost $50 \%$ of high grade tumors had survived only for 2 to 4 months. Rest of the cases are alive and are on chemotherapy.

\section{CONCLUSION}

In summary, this study confirms the prognostic value of the Weiss system. It is concluded that high grade tumors according to Weiss criteria are having poor prognosis and reduced five year survival rate, while low grade tumors are with good prognosis.

\section{REFERENCES}

1. Fuhrman SA, Lasky LC, Limas C. Prognostic significance of morphologic parameters in renal cell carcinoma. Am J Surg Pathol 1982;6:655-63.

2. Vargas MP, Vargas HI, Kleiner DE, Merino MJ. Adrenocortical neoplasms: Role of prognostic markers MIB-1, P53, and RB. Am J Surg Pathol 1997; 21: 556-62.

3. Tritos NA, Cushing GW, Heatley G, Libertino JA. Clinical features and prognostic factors associated with adrenocortical carcinoma: Lahey Clinic Medical Center experience. Am Surg 2000;66:73-9.

4. Weiss LM. Comparative histological study of 43 metastasizing and nonmetastasizing adrenocortical tumors. Am J Surg Pathol 1984;8:163-9.

5. Schteingart DE, Oberman HA, Friedman BA, Conn JW. Adrenal cortical neoplasms producing Cushing's syndrome. A clinicopathologic study. Cancer 1968;22:1005-13.

6. Cote RJ, Cordon-Cardo C, Reuter VE, Rosen PP. Immunopathology of adrenal and renal cortical tumors. Coordinated change in antigen expression is associated with neoplastic conversion in the adrenal cortex. Am J Pathol 1990;136:1077-84.
7. Gaffey MJ, Traweek ST, Mills SE et al.Cytokeratin expression in adrenocortical neoplasia. An immunohistochemical and biochemical study with implications for the differential diagnosis of adrenocortical, hepatocellular, and renal cell carcinoma. Hum Pathol 1992;23:144-53.

8. Gupta D, Shidham V, Holden J, Layfield L. Value of topoisomerase II alpha, MIB-1, p53, E-cadherin, retinoblastoma gene protein product, and HER-2/neu immunohistochemical expression for the predication of biologic behavior in adrenocortical neoplasms. Appl Immunohistochem Mol Morphol 2001;9:215-21.

9. Wick MR, Cherwitz DL, McGlennen RC, Dehner LP. Adrenocortical carcinoma. An immunohistochemical comparison with renal cell carcinoma. Am J Pathol 1986;122:343-52.

10. Renshaw AA, Granter SR: A comparison of A103 and inhibin reactivity in adrenal cortical tumors: distinction from hepatocellular carcinoma and renal tumors. Mod Pathol 1998;11:1160-64.

11. Medeiros LJ, Weiss LM. New developments in the pathologic diagnosis of adrenal corticalneoplasms. Am J Clin Pathol 1992;97:73-83.

12. Neville AM, Mackady AM. The structure of human adrenal cortex in health and disease. Clin Endocrinol 1972;1:361-95.

13. Gabrilove JR, Sharma DC, Wotiz HH, Dorfman RI. Feminising adrenocortical carcinomas in males. A review of 52 cases including a case report. Medicine 1965;44:37-9.

14. Lewinsky BS, Criger KM, Seyrnington T, Neville AM. The clinical and pathologic features of 'non-hormonal' adrenocortical tumours. Report of 20 new cases and review of the literature. Cancer 1974;33:778-90.

15. Schteingart DE, Metzedi A. Noonam RA, Thompson NW. Treatment of adrenocortical carcinomas. Arch Surg 1982;117:1142-5.

16. Harrison JH, Mahoney EM, Bennett AM. Tumours of the adrenal cortex. Cancer 1973;32:1227-35.

17. Correa P,ChenVW. Endocrine gland cancer. Cancer 1995;75:338-52.

18. Karakousis CP, Rao U, Moore R. Adrenal cortical carcinomas, histologic grading and survival. J Surg Oncol 1985;29:105-11.

19. Sullivan M, Boileau H, Hodges CV. Adrenal cortical carcinoma. J Urol 1978;120:660-5. 